\title{
Seabird behavior as an indicator of food supplies: sensitivity across the breeding season
}

\author{
Ann M. A. Harding ${ }^{1}$, John F. Piatt ${ }^{2, *}$, Joel A. Schmutz ${ }^{2}$ \\ ${ }^{1}$ Environmental Science Department, Alaska Pacific University, 4101 University Drive, Anchorage, Alaska 99508, USA \\ ${ }^{2}$ US Geological Survey, Alaska Science Center, 1011 East Tudor Road, Anchorage, Alaska 99503, USA
}

\begin{abstract}
We used empirical data on the time allocation of common murres Uria aalge in relation to measures of local prey density to examine whether adults provisioning chicks are more sensitive to changes in prey density than birds that are incubating eggs. We hypothesized that seasonal differences in food requirements of incubating and chick-rearing parents would affect the form of the relationship between time spent at the colony and local food density. We found that the relationship did differ between the incubation and chick-rearing period in 3 important ways: (1) there was a strong non-linear relationship between food density and colony attendance during chick-rearing and a weaker relationship during incubation; (2) incubating birds were able to maintain relatively constant rates of attendance over a wider range of food densities than chick-rearing birds and only reduced colony attendance under extremely poor feeding conditions, if at all; and (3) incubating birds spent more time attending nest sites at the colony than provisioning birds. These differences confirmed that chick-rearing parents are more sensitive to changes in food density than incubating parents, and that measurements of time allocation during the incubation period would have limited value as an indicator of ecosystem change.
\end{abstract}

KEY WORDS: Colony attendance · Prey density · Seabird · Uria aalge · Hydroacoustic surveys · Incubation $\cdot$ Provisioning $\cdot$ Chick-rearing

\section{INTRODUCTION}

Seabirds may be useful indicators of change in marine ecosystems when aspects of their biology or behavior respond in a predictable manner to changes in food availability (e.g. Durant et al. 2003, Frederiksen et al. 2004). The form of the relationship between a measurable behavioral or demographic parameter and local food supply largely determines the sensitivity and utility of that parameter as an indicator of marine ecosystem change (Cairns 1987). For example, the breeding success of several species of seabirds has been shown to be a non-linear function of food density (Philips et al. 1996, Suddaby \& Ratcliffe 1997, Piatt \& Harding 2007), with productivity linearly correlated with food over a limited range of poor to moderate food abundance, but plateauing and independent over a range of higher abundance.
Similarly, there is a non-linear relationship between food density and the amount of time common murres Uria aalge spend at the colony during the chick-rearing period (Harding et al. 2007). Breeding common murres have a fairly flexible time budget, with the nonbrooding parent able to increase foraging time in exchange for time spent at the colony when food is scarce (Burger \& Piatt 1990, Uttley et al. 1994, Zador \& Piatt 1999). Conversely, more time can be spent at the colony when food is abundant and foraging time is minimal. This flexibility results in a relationship where colony attendance increases rapidly as prey density increases over a range of low to moderate food densities until attendance levels off to become independent of prey over a range of moderate to higher densities (Harding et al. 2007). This plateau in attendance presumably reflects a trade-off between the costs (e.g. adult predation risk) and benefits (e.g. defending nest 
sites) of time spent at the colony (Cairns 1987, Jones et al. 2002, Davoren \& Montevecchi 2003).

Time and energy demands associated with reproduction are generally thought to be at a maximum during the chick-rearing period for altricial species (Ricklefs 1983), and parents may adjust their foraging time and behavior to cope with these increased demands (e.g. Jansen et al. 2002, Shaffer et al. 2003). For example, studies on the behavior of breeding murres have shown an increase in foraging effort and foraging rates, a decrease in time spent at the colony, alteration in diving behavior (e.g. dive interval), and a switching of prey species during the chick-rearing period (Gaston 1985, Croll et al. 1991, Zador \& Piatt 1999, Benvenuti et al. 2002, Jones et al. 2002). Given this increased demand for food, we assumed that timeactivity budgets of chick-rearing parents should be more sensitive to prey availability than incubating birds. To our knowledge, however, this assumption had never been tested.

In the present study we used empirical data on the parental time budgets of common murres to examine how time allocation changes with breeding status. We predicted that chick-rearing birds would decrease colony attendance at a higher threshold of food density than incubating parents. We defined this behavioral threshold as the level of food density below which there is a positive correlation between attendance and food density, and above which there is no such relationship. In order to ensure a broad range of food densities required to assess functional relationships, we designed a 5 yr study around 3 colonies with contrasting oceanographic conditions and an order of magnitude range in local food density (Abookire \& Piatt 2005, Speckman et al. 2005). We used 15 colony-years of data gathered in this study to characterize the functional relationship between time spent at the colony and food density and contrast the relationship between incubation and chick-rearing periods. We discuss the implications of these results for the use of seabirds as indicators of change in the marine environment and make specific recommendations for monitoring programs.

\section{MATERIALS AND METHODS}

Study sites and background. This study was conducted during 5 consecutive seasons (1995 to 1999) at 3 common murre Uria aalge colonies in lower Cook Inlet, Alaska (Speckman et al. 2005, Piatt \& Harding 2007), providing us with 15 colony-years of data. The colonies are separated from each other by about $100 \mathrm{~km}$, and are in oceanographically distinct habitats (Speckman 2004). Chisik Island is adjacent to stratified, relatively warm estuarine waters with low primary produc- tivity; Gull Island is adjacent to relatively cool, stratified and highly productive waters that are fed by cold currents from the south; and the Barren Islands are surrounded by mixed, cold oceanic waters that result from upwelling of Gulf of Alaska water as it enters Cook Inlet (Speckman et al. 2005). Common murres breeding at these colonies have shown contrasting population trends over the last 25 yr (Piatt \& Anderson 1996, Zador \& Piatt 1999).

By studying 3 colonies with order-of-magnitude differences in food availability in the surrounding waters (Abookire \& Piatt 2005, Speckman et al. 2005), our study constituted a natural experiment to resolve the relationship between seabirds and their food supply (see Harding et al. 2007 for more details).

Local prey density. We measured local fish densities around each of 3 seabird colonies by conducting hydroacoustic surveys on a grid of transects arranged within a $50 \mathrm{~km}$ radius of each site (details are found in Speckman 2004, Speckman et al. 2005, Harding et al. 2007). Distances surveyed among areas were similar, averaging about 1100 linear $\mathrm{km}$ of transect for all areas combined in each year except for 1995 (750 km surveyed; Speckman 2004, J. F. Piatt unpubl. data). Hydroacoustic surveys were conducted during a $3 \mathrm{wk}$ period in each year (1995: 10 to 23 August; 1996: 14 to 31 July; 1997: 19 July to 8 August; 1998: 21 July to 12 August; 1999: 25 July to 16 August), usually encompassing periods of late incubation and early chick rearing for common murres (overall colony/year mean date of hatch was 10 August; J. F. Piatt \& A. B. Kettle unpubl. data). We assumed therefore that hydroacoustic biomass estimates reflect food densities during both incubation and chick-rearing.

Hydroacoustic data were collected with a single beam $120 \mathrm{kHz}$ BioSonics DT4000 system with a $6^{\circ}$ beam angle. Before each cruise, the acoustic system was calibrated using a $33.2 \mathrm{~mm}$ tungsten carbide sphere with expected target strength of $-40.6 \mathrm{~dB}$. To identify acoustic signals and measure the size of individual fish, we conducted 163 mid-water trawls (see Abookire \& Piatt 2005, Speckman et al. 2005). Acoustic data were analyzed using SonarData Echoview software (Ver. 2.10.48) and integrated with a minimum threshold of $-70 \mathrm{~dB}$ to obtain relative measures of acoustic biomass $\left(S_{\mathrm{A}}\right)$. These were converted to absolute estimates of fish density (fish $\mathrm{m}^{-3}$ ) by dividing $S_{\mathrm{A}}$ by $\sigma$ (backscattering cross-sectional area of single prey) for species with the following known target strengths (TS): pollock TS $=21.1 \log (L)-70.5$, herring TS $=202.0 \log (L)-67.6$, and capelin TS $=28.4 \log (L)-$ 81.8 (all from Gauthier \& Horne 2004), sandlance TS = 20.0Log $(L)-80$ (Thomas et al. 2002), and $\operatorname{cod}$ TS = 20.0Log $(L)-65$ (Rose \& Leggett 1988), which accounted for $99.2 \%$ of all fish caught. The proportion of catch, 
expressed as catch per unit effort, standardized to the number captured per $\mathrm{km}$ trawled, was used to convert acoustic backscatter to species-specific fish density $\left(\mathrm{g} \mathrm{m}^{-3}\right)$ (Speckman 2004). Geometric mean acoustic densities were calculated from transformed data as mean $(\log x+1)$ values, and then transformed back to original density units (Johannesson \& Mitson 1983).

Parental behavior. We measured parental time spent at the colony during the chick-rearing period in each of the 15 colony-years and during incubation in 14 colonyyears (data not collected at the Barren Islands in 1995). Data were collected by direct observations of murres on Chisik Island and indirectly with a time-lapse video camera on Gull Island (see Zador \& Piatt 1999). Murres at the Barren Islands were observed directly in 1995 and by time-lapse video from 1996 to 1999. Video resolution (5 frames s${ }^{-1}$ at the Barrens, 6 frames s${ }^{-1}$ at Gull Island) was sufficient to record all arrivals and departures of birds at the colony.

Birds at each colony were observed on a plot containing 7 to 12 breeding pairs of murres from 07:00 to 20:00 Alaska Daylight Time on 2 to 3 observation days during both the incubation and chick-rearing phases. We observed the same nest sites within each summer, although failed nests were replaced in later watches. Observation days were generally scheduled to sample the early, middle, and late parts of both the incubation and chick-rearing periods.

We noted each parent's arrival and departure time at the colony. Attendance was measured in bird-minutes per hour. For example, if 1 incubating or brooding parent attended its nest for a full hour, and the off-duty partner attended for half of that hour, we calculated 90 bird-minutes of attendance for that hour. Fewer than 60 bird-minutes of attendance would mean that the egg or chick was left unattended for some period of time. Nest site was a sample unit, with mean colony attendance per nest calculated separately for the incubation and chick-rearing periods.
Statistical analysis. Our prediction - that below a certain threshold food density is positively related to colony attendance, whereas above this threshold there is no such relationship-mathematically implies a non-linear model of the relation between these 2 variables. This model, heuristically depicted by Cairns (1987), can be more precisely described quantitatively as a piecewise or broken-stick model (Toms \& Lesperance 2003) that represents the joining of 2 segments, the first of which is represented by a quadratic equation and the second of which is a flat asymptote or plateau of no slope. We used a quadratic model, rather than a linear one, for the first segment to allow for a smooth transition to the plateau. Two alternatives to this non-linear model can be contemplated. One is a null model of no relation, which is essentially the plateau segment of the non-linear model. The other is a linear model, which is analogous to just the first segment of the nonlinear model and implies that the range of observed food densities affects time spent at the colony.

We compared the fit of these 3 models (Table 1 ) to colony mean values of incubation and chick-rearing attendance data using the Akaike information criterion, adjusted for finite sample size (AICc), and for which the model with the lowest AICc best represents the data (Burnham \& Anderson 2002). Each model was statistically represented with a least-squares regression model where the error sums of squares, sample size, and number of estimated parameters all influenced the AICc calculation (Burnham \& Anderson 2002). For each model we also present an AICc weight, which reflects the relative likelihood of that model being the best fitting model among those considered and where all AICc weights within an analysis sum to 1. These AICc weights allowed us to employ modelaveraging procedures, which are useful when competing models fit the data similarly (Burnham \& Anderson 2002).

Table 1. Uria aalge. Comparison of the relationship between food density and time spent at the colony during the incubation and chick-rearing periods. Three predicted relationships were tested by comparing the fit of colony-mean annual values to the models illustrated using the Akaike information criterion (AIC). The best fitting model for each predicted relationship appears in bold. Model-averaged fits to the data for the non-linear relationship are shown in Fig. 1

\begin{tabular}{|c|c|c|c|c|c|c|}
\hline \multirow{2}{*}{\multicolumn{2}{|c|}{$\begin{array}{l}\text { Relationships } \\
\text { Food density } x \text {-axis }\end{array}$}} & \multirow{2}{*}{\multicolumn{3}{|c|}{ Predicted models evaluated }} & \multirow{2}{*}{\multicolumn{2}{|c|}{$\begin{array}{l}\text { Values from non-linear } \\
\text { relationships }\end{array}$}} \\
\hline & & & & & & \\
\hline & & $\swarrow_{\text {Non-linear }}$ & Null & Linear:positive & $\begin{array}{l}\text { Food threshold } \\
\qquad\left(\mathrm{g} \mathrm{m}^{-3}\right)\end{array}$ & $\begin{array}{l}\text { Attendance plateau } \\
\quad\left(\text { bird-min } \mathrm{h}^{-1} \text { ) }\right.\end{array}$ \\
\hline \multirow[t]{3}{*}{ Incubation } & $\Delta$ AICc value & 1.32 & 0.00 & 1.78 & 0.033 & 75.20 \\
\hline & AICc weight & 0.27 & 0.52 & 0.21 & & \\
\hline & $\mathrm{r}^{2}$ & 0.35 & 0.0 & 0.10 & & \\
\hline \multirow[t]{3}{*}{ Chick-rearing } & $\Delta$ AICc value & 0.00 & 8.80 & 1.85 & 0.058 & 72.13 \\
\hline & AICc weight & 0.65 & 0.01 & 0.28 & & \\
\hline & $\mathrm{r}^{2}$ & 0.71 & 0.00 & 0.49 & & \\
\hline
\end{tabular}




\section{RESULTS}

\section{Local food density}

Mean prey density varied among the 15 colonyyears $\left(\right.$ mean $=0.0353 \mathrm{~g} \mathrm{~m}^{-3} \pm 0.006 \mathrm{SE}, \mathrm{CV}=0.69$ ). Overall mean prey density (1995 to 1999) differed significantly among the 3 colonies (ANOVA: $F_{2,12}=5.91$, $\mathrm{p}=0.016$ ), with food density at Gull Island usually higher than that at either Chisik Island or the Barren Islands (Tukey multiple comparison test: $p<0.05$; Chisik mean $=0.0138 \mathrm{~g} \mathrm{~m}^{-3} \pm 0.002 \mathrm{SE}_{\text {; }}$ Barren mean $=$ $0.0383 \mathrm{~g} \mathrm{~m}^{-3} \pm 0.008 \mathrm{SE}_{\text {; Gull mean }}=0.0540 \mathrm{~g} \mathrm{~m}^{-3} \pm$ $0.012 \mathrm{SE})$.

\section{Functional relationships}

There was a weak relationship between time spent at the colony during incubation and food density, and, overall, the null model best fit the data. However, the model-averaged depiction of the relationship between food density and attendance has a semblance of nonlinearity (Fig. 1). Birds actually maintained a fairly con-

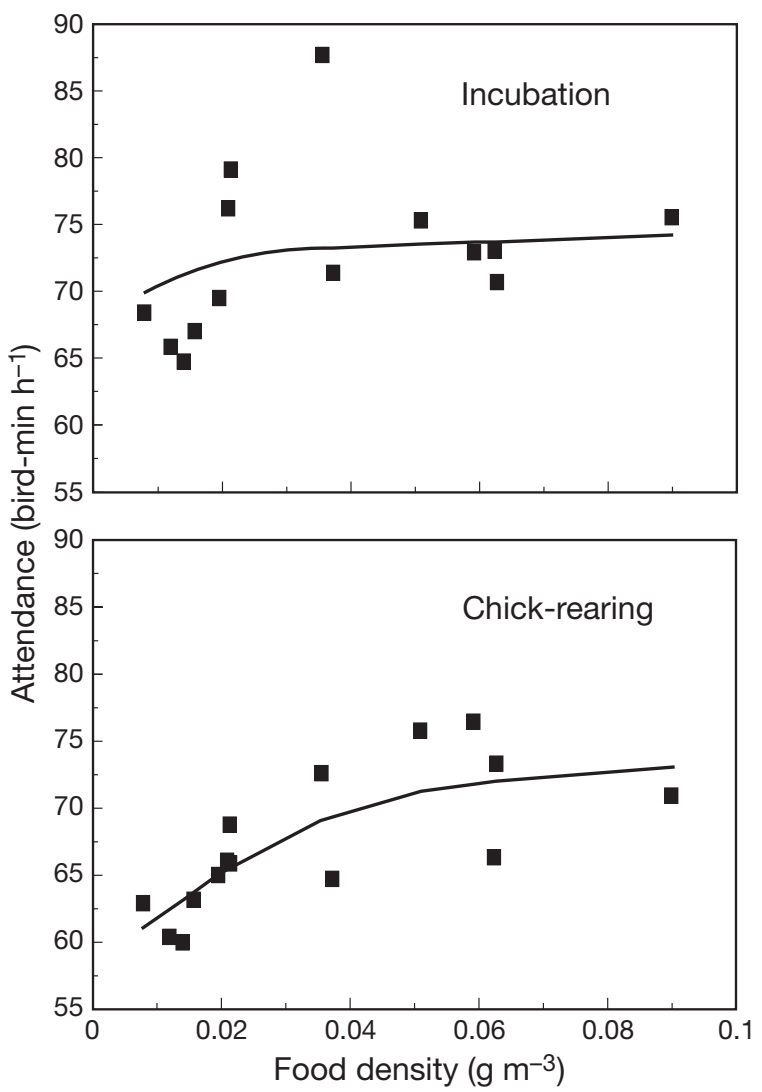

Fig. 1. Uria aalge. Model-averaged fit of the non-linear relationship between attendance during incubation and chickrearing versus local prey density. Fitted values for modelaverage based on Akaike information criterion weights stant level of colony attendance over a broad range of food densities (null relationship) and reduced the time spent at the colony only when food reached the extreme lower range of densities measured in this study (Fig. 1). When examining parameter estimates from this poorer fitting non-linear model $(\triangle \mathrm{AICc}=$ 1.32), the threshold of $0.0334 \mathrm{~g} \mathrm{~m}^{-3}$ food density is lower than the threshold observed during chick-rearing. Above this threshold, birds maintained attendance at a rate of 75.20 bird-minutes $\mathrm{h}^{-1}$ over a broad range of higher densities. This equates to $4 \mathrm{~h}$ spent at the nest site by the non-incubating bird in a $16 \mathrm{~h}$ day.

In contrast, time spent at the colony during chickrearing varied non-linearly with food availability (Table 1, Fig. 1). Overall, the non-linear model best fit the chick-rearing data $(\triangle \mathrm{AICC}>1.0$ for competing models). Time spent at the colony increased linearly with food over a poor to moderate range of prey densities, but was largely independent of food density above $0.058 \mathrm{~g} \mathrm{~m}^{-3}$, the estimated threshold from this bestfitting model. This threshold corresponded to an asymptotic attendance rate of 72.13 bird-minutes $\mathrm{h}^{-1}$ over a wide range of moderate to high food densities (in contrast to 75.20 bird-minutes $\mathrm{h}^{-1}$ during incubation), suggesting that the non-brooding parent would have to spend $12 \mathrm{~min}^{-1}$ at the nest site, an equivalent of ca. $3 \mathrm{~h}$ of colony time in a $16 \mathrm{~h}$ day. The off-duty parent therefore spends ca. $1 \mathrm{~h}$ (in a $16 \mathrm{~h}$ day) less time at the colony over moderate to good feeding conditions than incubating parents.

\section{DISCUSSION}

The relationship between colony attendance of Uria aalge and local food density differed between the incubation and chick-rearing period in 3 important ways: (1) there was a strong non-linear relationship between food density and colony attendance during chickrearing and a weaker relationship during incubation; (2) incubating birds were able to maintain relatively constant rates of attendance over a wider range of food densities than chick-rearing birds, and only reduced colony attendance under extremely poor feeding conditions, if at all; and (3) incubating birds spent more time attending nest sites at the colony than provisioning birds. The first 2 differences indicate that chick-rearing parents are more sensitive indicators of food abundance than incubating parents, and further suggest that measurement of time allocation during the incubation period will have limited value as an indicator of ecosystem change. We assume that incubating birds were able to balance social requirements of time spent at the colony with energy demands at a lower threshold of food density than parents provisioning chicks. 
The decrease in time spent at the colony during chick-rearing most likely reflects an increase in time spent foraging. Provisioning parents must increase foraging effort in order to provide an average of 4 daily meals to their chick (Harris \& Wanless 1988, Burger \& Piatt 1990) and also to satisfy the resulting increase in their own energy requirements (Gaston 1985, Benvenuti et al. 2002). Alternatively, the lower colony attendance during chick-rearing could be explained by reduced benefits of time spent at the colony. This seems unlikely, however, because the number of immature and non-breeding murres at a colony increases during late chick-rearing (Gaston \& Nettleship 1982, Harris et al. 1986), and the importance of nest-site defense is therefore presumably high.

Knowledge of the shape or form of functional relationships is essential for interpreting species-specific responses to a changing environment. Behavioral or demographic parameters can provide a useful indication of environmental change only if we can predict the range of food availability to which they respond. It is also important to determine the optimal time of the breeding season for monitoring indicator parameters. Functional relationships are usually non-linear (Holling 1959, Hassel \& May 1974), and therefore most measures of foraging effort only reflect a change in food availability when densities are low and food is limiting. Chick-rearing birds have higher food requirements than incubating birds and therefore broaden the range over which food density is related to colony attendance. We suspect that other behavioral parameters that reflect food acquisition may also respond to a broader range of food densities during the chickrearing period.

Direct measures of foraging effort using activity recorders or telemetry (e.g. Benvenuti et al. 2002, Falk et al. 2002) may provide a more accurate index of local food abundance than observations of colony attendance (Cairns 1987, Monaghan et al. 1994), but we observed a strong correlation between chick-rearing colony attendance and food density over a relatively wide range of low to moderate prey densities. Furthermore, methods for collecting data on time budgets are non-invasive, relatively inexpensive, and straightforward. This means they would be relatively easy to incorporate into long-term monitoring programs that use integrated approaches to detect change in the marine environment (e.g. Hare \& Mantua 2000, Golet et al. 2004).

Acknowledgements. We thank the many researchers who spent long hours murre-watching. In particular, we thank A. Kettle, M. Shultz, T. Van Pelt, and S. Zador for coordinating data collection at the colonies and S. Speckman for the hydroacoustic surveys. We thank G. Snedgen, B. Keitt, the staff of Kasitsna Bay Marine Lab, and the residents of Chisik Island, Tuxedni Channel, Halibut Cove, and Kasitsna Bay for their support, M. Whalen for the graphics, and M. Litzow, S. Hatch, S. Speckman, and 3 anonymous referees for thoughtful reviews. Any use of trade names is for descriptive purposes only, and does not imply endorsement of the US Government. Funding and logistic support were provided by the Alaska Science Center (USGS), the Alaska Maritime National Wildlife Refuge (USFWS), and the Exxon Valdez Oil Spill Trustee Council (APEX Restoration Project 96163M and 96163J).

\section{LITERATURE CITED}

Abookire AA, Piatt JF (2005) Oceanographic conditions structure forage fish into lipid-rich and lipid-poor communities in lower Cook Inlet, Alaska, USA. Mar Ecol Prog Ser 287: $229-240$

Benvenuti S, Dall'Antonia L, Falk F (2002) Diving behaviour differs between incubating and brooding Brunnich's guillemots, Uria lomvia. Polar Biol 25:474-478

Burger AE, Piatt JF (1990) Flexible time budgets in breeding common murres: buffers against variable prey abundance. Stud Avian Biol 14:71-83

Burnham KP, Anderson DR (2002) Model selection and multimodel inference: a practical information-theoretic approach. Springer-Verlag, New York

Cairns DK (1987) Seabirds as monitors of marine food supplies. Biol Oceanogr 5:261-271

Croll DA, Gastin AJ, Noble DG (1991) Adaptive loss of mass in thick-billed murres. Condor 93:496-502

Davoren GK, Montevecchi WA (2003) Consequences of foraging trip duration on provisioning behavior and fledging condition of common murres Uria aalge. J Avian Biol 34: $44-53$

Durant JM, Anker-Nilssen T, Stenseth NC (2003) Trophic interactions under climate fluctuations: the Atlantic puffin as an example. Proc R Soc Lond B 270:1471-2954

Falk K, Benvenuti S, Dall'Antonia L, Gilchrist G, Kampp K (2002) Foraging behaviour of thick-billed murres breeding in different sectors of the North Water polynya: an intercolony comparison. Mar Ecol Prog Ser 231:293-302

Frederiksen M, Harris, MP, Daunt F, Rothery P, Wanless S (2004) Scale-dependent climate signals drive breeding phenology of three seabird species. Global Change Biol 10:1214-1221

Gaston AJ (1985) Energy invested in reproduction by thickbilled murres (Uria lomvia). Auk 102:447-458

Gaston AJ, Nettleship DN (1982) Factors determining seasonal changes in attendance at colonies of the thick-billed murre (Uria lomvia). Auk 99:468-473

Gauthier S, Horne JK (2004) Acoustic characteristics of forage fish species in the Gulf of Alaska and Bering Sea based on Kirchhoff-approximation models. Can J Fish Aquat Sci 61:1839-1850

Golet GH, Schmutz JA, Irons DB, Estes JA (2004) Determinants of reproductive costs in the long-lived black-legged kittiwake: a multiyear experiment. Ecol Monogr 74: 353-372

Harding AMA, Piatt JF, Schmutz JA, Shultz M, Van Pelt TI, Kettle AB, Speckmann SG (2007) Prey density and the behavioural flexibility of a marine predator: the common guillemot (Uria aalge). Ecology 88:2024-2033

Hare SR, Mantua NJ (2000) Empirical evidence for North Pacific regime shifts in 1977 and 1989. Prog Oceanogr 47: 103-145 
Harris MP, Wanless S (1988) The breeding biology of guillemots (Uria aalge) on the Isle of May over a six year period. Ibis 130:172-192

Harris MP, Wanless S, Rothery P (1986) Counts of breeding and nonbreeding guillemots (Uria aalge) at a colony during the chick rearing period. Seabird 9:43-46

Hassell MP, May RM (1974) Aggregation of predators and insect parasites and its effect on stability. J Anim Ecol 43:567-594

Holling CS (1959) The components of predation as revealed by a study of small mammal predation of the European pine sawfly. Can Entomol 91:293-320

Jansen JK, Russel RW, Meyer WR (2002) Seasonal shifts in the provisioning behavior of chinstrap penguins (Pygoscelis antarctica). Oecologia 131:306-318

Johannesson KA, Mitson RB (1983) Fisheries acoustics: a practical manual for aquatic biomass estimation. FAO Fish Tech Pap 240:1-249

Jones IL, Rowe S, Carr SM, Fraser G, Taylor P (2002) Different patterns of parental effort during chick-rearing by female and male thick-billed murres (Uria lomvia) at a low-arctic colony. Auk 119:1064-1074

Monaghan P, Walton P, Wanless S, Uttley JD, Burns MD (1994) Effects of prey abundance on the foraging behavior, diving efficiency and time allocation of breeding guillemots (Uria aalge). Ibis 136:214-222

Philips RA, Caldow RWG, Furness RW (1996) The influence of food availability on the breeding effort and reproductive success of Arctic skuas (Stercorarius parasiticus). Ibis 138: 410-419

Piatt JF, Anderson P (1996) Response of common murres to the Exxon Valdez oil spill and long-term changes in the Gulf of Alaska marine ecosystem. Am Fish Soc Symp 18: $720-737$

Editorial responsibility: Howard Browman (Associate Editorin-Chief), Storebø, Norway
Piatt JF, Harding AMA (2007) Population ecology of seabirds in Cook Inlet. In: Spies R (ed) Long-term ecological change in the northern Gulf of Alaska. Elsevier, Amsterdam, p 335-352

Ricklefs RE (1983) Some considerations on the reproductive energetics of pelagic seabirds. Stud Avian Biol 8:84-94

Rose GA, Leggett WC (1988) Hydroacoustic signal classification of fish schools by species. Can J Fish Aquat Sci 45: $597-604$

Shaffer SA, Costa DP, Weimerskirch H (2003) Foraging effort in relation to the constraints of reproduction in free-living albatross. Funct Ecol 17:66-74

Speckman SG (2004) Characterizing fish schools in relation to the marine environment and their use by seabirds in lower Cook Inlet, Alaska. PhD thesis, University of Washington, Seattle

Speckman SG, Piatt JF, Minte-Vera CV, Parrish JK (2005) Parallel structure among environmental gradients and three trophic levels in a subarctic estuary. Prog Oceanogr 66: 25-65

Suddaby RM, Ratcliffe N (1997) The effects of fluctuating food availability on breeding Arctic terns (Sterna paradisaia). Auk 114:524-530

Thomas GL, Kirsch J, Thorne RE (2002) EX-situ target strength measurements of Pacific herring and Pacific sand lance. North Am J Fish Manage 22:1136-1145

Toms JD, Lesperance ML (2003) Piecewise regression: a tool for identifying ecological thresholds. Ecology 84:2034-2041

Uttley JD, Walton P, Monaghan P, Austin G (1994) The effects of food abundance on breeding performance and adult time budgets of guillemots (Uria aalge). Ibis 136:205-215

Zador SG, Piatt JF (1999) Time-budgets of common murres at a declining and increasing colony in Alaska. Condor 101:149-152

Submitted: September 29, 2006; Accepted: March 2, 2007 Proofs received from author(s): September 18, 2007 